\title{
Financial Risk Analysis of Portuguese Textile and Tourism Companies
}

\author{
José Manuel Pereira
}

IPCA - Polytechnic Institute of Cávado and Ave, High School of Management, CICF, Campus do IPCA, 4750-810 Barcelos, Portugal

Mário Basto

IPCA - Polytechnic Institute of Cávado and Ave, High School of Technology, Campus do IPCA, 4750-810 Barcelos, Portugal

\section{Amélia Ferreira-da-Silva}

IPP - Polytechnic Institute of Porto, Institute of Accounting and Administration of Porto, CEPESE, CECEJ, Rua Jaime Lopes Amorim, S/N 4665-004 Porto, Portugal

\section{Humberto Ribeiro}

GOVCOPP \& College of Technology and Management, Aveiro University, Rua Comandante Pinho e Freitas, n. 28 , 3750 - 127, Águeda, Portugal

\section{Doi:10.5901/mjss.2015.v6n3p471}

Abstract

Textile and tourism sectors are two important industries in the Portuguese economy. However, its high exposure to both internal and international economic volatility make the companies operating in these economic sectors particularly vulnerable to economic crises, such as the ones which have been impacting Portugal and the European Union. The objective of this paper is to evaluate and understand the impact of size and age on the financial health of textile and tourism companies, measured by economic indices. An empirical based model is proposed. Its implications are derived and tested on a sample of 4061 Portuguese companies from textile and tourism sectors, during the period 2005-2009. The findings suggest that age has a major impact on the risk of failure, rather than size. Whereas the effect of age is generally positive regarding the financial health of the company, the effect of size is less clear and ultimately depends on the age of the company.

Keywords: Age, size, business failure, textiles and tourism.

\section{Introduction}

Although the first empirical studies of bankruptcy prediction have been developed around the thirties by Fitzpatrick (1932) and Smith and Winakor (1935), the topic gained a new visibility and new academic relevance in the sixties, with the researches of Beaver (1966) and Altman (1968). Since then a growing number of researchers has investigated on this topic.

At a time when the national and international scene is marked by an economic and financial crisis, and in times of market downturn and economic difficulties, to understand why some companies fail and others don't, is a topic of extreme interest. The economic consequence of company's failure is enormous, especially for employees, investors and creditors.

During the last four decades a growing number of researches came up with formulas to predict the bankruptcy of a company. The set of predictive variables proposes on the studies is considerably heterogeneous. Age and size are two variables well investigated, however previews research is not clear about how age and size affects business failure, especially we do not know how these models perform when tested with Portuguese companies.

The objective of this paper is to evaluate and understand the impact of size and age on the financial health of textile and tourism companies, measured by economic indices, and therefore also evaluates their risk of failure. Its implications are derived and tested on a sample of 4061 Portuguese companies from textile and tourism sector. 


\section{Literature Review}

It can be said that in all these decades of empirical research on bankruptcy prediction failed to produce agreement on which variables are good predictors and why (Hol et al., 2002). However, in all those models mentioned above, there are several works that, through different perspectives consider size, age and sector as key variables to explain the probability of failure and growing businesses.

Some studies have concluded that the size is negatively correlated with the probability of failure (Thompson, 1976; Altman et al., 1977; Ohlson, 1980; Evans, 1987; Hall, 1987; Chen and Lee, 1993; Audretsch and Mahmood 1995; Cummins et al., 1995 or Turetsky and McEwen, 2001).

Chen and Wong (2004) reported that one of the main factors which significantly affect the financial health of companies is its size. Honjo (2000) used a proportional hazards model to show that software companies with an important size are less likely to fail. Turetsky and McEwen (2001) argue that large firms are expected to have better risk management. For Berger and Udell (1995), the oldest the company is, the lower are costs of external financing. In the same sense, Holmes et al. (1994) mention that smaller companies often have more limited access to financing and a greater financial cost. Mazzi (2011) reported that family firms are, in general, significantly younger than nonfamily firms. Similar finding was obtained by Villalonga and Amit (2006), Lee (2006) and Miller et al. (2007).

Serrano et al. (2005) argue that small firms are more likely to fail than large enterprises. The authors added that the ratios depend on the size of the company, but the way it does it, varies over different countries. Buehler et al. (2006) found that the percentage of companies that fail decrease with age.

In the literature on corporate risk there are also authors who use size as an explanatory variable in their models of business failure prediction (Ohlson , 1980; Peel et al., 1986; Peel and Peel, 1988 or López et al., 1998).

The results obtained by Audretsch and Mahmood (1995) suggest that exposure to the risk of new firms tend to be larger in highly innovative sectors. These authors argue that new firms can reduce the risk of failure by increasing their size, indicating that the structure of ownership and size of young companies have influence on the probability of survival. Audretsch (2001) finds that young companies do not have economies of scale. He also states that some companies manage to successfully grow and others remain small and ultimately may have to exit the market.

On the subject we also highlight the contributions of Fariñas and Moreno (2000) and Calvo and Garcia (2006). Using a sample of Spanish companies Fariñas and Moreno (2000) concluded that the failure of firms declines with age and size. Calvo and Garcia (2006) carried out an empirical study to analyze the structure of financial risk the Spanish industry in the period 1997-2001, analyzing the impact of the size and age of the company. The findings of the will towards the existence of an inverse relationship between the size and age of the company and its financial risk. Concerning the impact that causes the size and age of the company on risk variables analyzed, these authors concluded that the size factor is more relevant than the ability to return the ancient debt and economic profitability of the company, and a higher incidence in antiquity capitalization and financial stability of the companies.

\section{Metodology}

\subsection{Selection of the sample}

To develop this study, we used the information of the annual accounts (balance sheet and income statement) collected from the SABI database. The sample comprises 4061 companies from sectors of textile and tourism. The information collected refers to the year 2005-2009.

\subsection{Variables}

The variables are the size and age. The variable age measures the time in years since the constitution of the company till the year of 2009. This variable is categorized in three categories: less than 5 years, between 5 and 15 years and more than 15 years.

For the size of the companies we follow the Commission Recommendation 96/280/EC of 3 April 1996, considering four categories. The size of the company is measured also in an ordinal scale: micro companies, small companies, medium companies and large companies. However, due to the inexistence of large companies with less than 5 years, and the relative very low frequency of large companies in the sample, the analysis was performed excluding those companies. Hence only three categories for size were considered in the analysis.

Five continuous indices were collected to measure the financial health of the company. These five variables have a 
great power to discriminate and classify the financial state and the risk of failure of the company according to Calvo and Garcia (2006).

These indices are:

X1 = (Net profit + Depreciation expense + Provisions) / Liabilities;

$\mathrm{X} 2=($ Current assets - Current Liabilities $) /$ Total assets;

$\mathrm{X} 3=$ Equity /Total assets;

X4 = Operating profit (or loss) / Total assets.

\subsection{Statistical Analysis}

Since there are four metric dependent variables (the four indices) and two ordinal predictor variables (size and age), the first goal is to evaluate the significance of the differences across groups defined by the predictor variables, to be able to conclude the significance of the impact of at least one of the predictor variables (size or age) on the indices measured.

Univariate analysis of variance (ANOVA) is a statistical technique that is used to determine whether samples are drawn from populations with equal means, so it is the adequate statistical instrument to evaluate the impact of predictors on each of the five dependent variables separately. This approach has the disadvantage of ignoring the possibly correlation between the dependent variables, and so a significant or nonsignificant ANOVA may be identified erroneously.

When one wants to simultaneously explore the relationship between several categorical independent variables and two or more continuous dependent variables, the statistical technique recommended is the multivariate analysis of variance (MANOVA), which is an extension of ANOVA. MANOVA procedure optimally combines the multiple dependent variables into a single value that maximizes the differences across groups, assessing how the dependent variables differ as a whole across the categories of the independent ones. Only after a significant MANOVA individual ANOVAs are performed to evaluate the impact of predictors on each of the dependent variables.

Therefore, MANOVA seems to be the adequate procedure as a starting point of the present study, as MANOVA can detect differences among the dependent variables, even when univariate tests show no differences. If a significant difference is achieved, separate ANOVAs can be employed to address the individual differences for each dependent variable.

Before applying these statistical procedures, it is important to check the presence of outliers. ANOVA and MANOVA are especially sensitive to outliers and their effect on Type I error.

The assumption of univariate normality in case of ANOVA or multivariate normality in case of MANOVA must be also checked. As in ANOVA, MANOVA tests are believed to be robust against violations of multinormality when the individual group sizes are large enough, which means that the impact on the final results are negligible. Monte Carlo studies (Mardia 1971; Olson 1974) show that departures from multivariate normality of MANOVA test statistics may reduce statistical power, but generally with only small effects on the type I error.

The next issue to be addressed is the equality levels of variance (in the case of one dependent variable, ANOVA) or equality of the covariance matrices (in the case of multiple dependent variables, MANOVA) across the groups, so that the variance (ANOVA) or the covariance matrices (MANOVA) for each group, are not concentrated in only a limited range of the categories of the predictor variables. If unequal variance/covariance across groups is present, the standard errors are affected and consequently the results of the tests. The effect of this is more severe when the sample size of the groups are small or very different.

In the present study some extreme points for each group were identified and eliminated prior to the analysis. The assumption that the data on each group conforms to a multivariate normal was checked and found to be violated. The same happens with the univariate normality distributions. The equality of the covariance matrices is also not met, nor the equality of variances for each of the dependent variables.

With these obstacles it is advisable to perform alternative procedures.

A nonparametric method, based on permutation tests, permutational MANOVA (McArdle, 2001; Anderson, 2001) was performed. For the permutational MANOVA (Anderson, 2001) the test statistic is a multivariate analogue to Fisher's F-ratio. The p-values are estimated using permutations. Under a true null hypothesis, the groups of multivariate observations can be exchangeable. Thus, permutations are performed to achieve new values for the statistic, giving the entire distribution of the statistic under a true null hypothesis.

This test is a test for differences in location among groups of multivariate observations. The test requires that the observations are independent and that they have similar distributions. It does not require the assumption of multivariate normality as MANOVA does. However, this test (as the parametric one) is sensitive to heterogeneity of variances. This means that a significant difference among groups may be due to differences in dispersion and/or differences in location. 
Although the statistic sensitivity to differences in variances among groups, it takes no account on the covariances among variables, as the parametric MANOVA (which assumes not only the equality of the variances but also that the covariances of the variables do not differ across groups) (Anderson, 2001). Hence, this test is less demanding concerning assumptions than the parametric MANOVA. The test was performed resorting on the vegan $\mathrm{R}$ package (R, 2011; Oksanen et al., 2013)

The results achieved by the permutational MANOVA are resumed in table 1

Table 1. Permutational MANOVA

\begin{tabular}{|c|c|c|c|}
\hline & Degrees of freedom & Sums of squares & -value \\
\hline Size & 2 & 5.62 & 0.008 \\
\hline Age & 2 & 34.41 & 0.001 \\
\hline Size Age & 4 & 7.84 & 0.009 \\
\hline
\end{tabular}

The interaction term represents the joint effect on the dependent variables of the two predictors, size and age. If the interaction is nonsignificant the effects of the factors are Independent, which means that the effect of one factor is the same for each level of the other factor and the main effects can be interpreted directly. The result $(p=0.009)$ points to the existence of strong evidence of interaction between size and age. Hence, the main effects of size and age must be interpreted with caution. Those main effects show that the variable age shows a little stronger impact than size over the dependent variables.

A parametric MANOVA was also performed (table 2), despite the unmet assumptions, to compare to the results obtained by the permutational MANOVA. The results show moderate to strong evidence of interaction, confirming the findings already obtained with the permutational MANOVA. Concerning the main effects, the outcome points to a nonsignificant result concerning size, and reinforces the strong effect of age (table 2) achieved by the preceding test.

Table 2. MANOVA

\begin{tabular}{|c|c|c|c|}
\hline & & Statistic & p-value \\
\hline \multirow{2}{*}{ Size } & Pillai's Trace & 0.002 & 0.344 \\
& Wilks' Lambda & 0.998 & 0.344 \\
& Hotelling's Trace & 0.002 & 0.344 \\
& Roy's Largest Root & 0.002 & 0.111 \\
\hline \multirow{2}{*}{ Age } & Pillai's Trace & 0.027 & $<0.001$ \\
& Wilks' Lambda & 0.973 & $<0.001$ \\
& Hotelling's Trace & 0.028 & $<0.001$ \\
& Roy's Largest Root & 0.026 & $<0.001$ \\
\hline Size*Age & Pillai's Trace & 0.008 & 0.018 \\
& Wilks' Lambda & 0.992 & 0.018 \\
& Hotelling's Trace & 0.008 & 0.018 \\
& Roy's Largest Root & 0.006 & $<0.001$ \\
\hline
\end{tabular}

As both MANOVAs show significant results, the study of the impact of size and age on each of the four dependent variables is required. As the sampled populations have distributions away from normality and do not have similar variances, four permutational ANOVAs and four two-way ANOVAs were undertaken and compared. Moreover, the results were also reported by a robust alternative to the sample mean and median for estimating the location (Huber's Mestimator) for each of the dependent variables.

Table 3 displays the results obtained by the parametric and permutational ANOVAs with both main and interaction effects. 
Table 3. Univariate ANOVAs (parametric and permutational ANOVAs)

\begin{tabular}{|c|c|c|c|c|c|}
\cline { 3 - 6 } \multicolumn{2}{c}{} & \multicolumn{2}{c|}{ Parametric ANOVAs } & \multicolumn{2}{c|}{ Permutational ANOVAs } \\
\hline Independent & Predictors & Sums of Squares & p-value & Sums of Squares & $p$-value \\
\hline \multirow{3}{*}{ x1 } & Size & 0.279 & 0.573 & 0.98 & 0.131 \\
& Age & 1.747 & 0.030 & 1.39 & 0.061 \\
& Size*Age & 1.173 & 0.320 & 1.17 & 0.317 \\
\hline \multirow{4}{*}{ x2 } & Size & 1.907 & 0.028 & 0.73 & 0.262 \\
& Age & 16.208 & 0.000 & 14.40 & 0.001 \\
& Size*Age & 3.591 & 0.009 & 3.59 & 0.015 \\
\hline \multirow{4}{*}{ x3 } & Size & 0.318 & 0.492 & 3.67 & 0.003 \\
& Age & 16.966 & 0.000 & 18.52 & 0.002 \\
& Size*Age & 2.647 & 0.019 & 2.65 & 0.025 \\
\hline \multirow{3}{*}{ x4 } & Size & 0.036 & 0.460 & 0.240 & 0.007 \\
& Age & 0.086 & 0.160 & 0.090 & 0.128 \\
& Size*Age & 0.430 & 0.001 & 0.430 & 0.011 \\
\hline
\end{tabular}

Only variable X1 show no evidence of interaction between size and age. By checking the sum of squares and the $\mathrm{p}$ values of each dependent variables, it is patent the bigger importance of age over size in explaining the financial risk of failure, except for variable $X 4$, where size becomes significant $(p=0.007)$ for the permutational ANOVA. This result must be interpreted with caution, since this is also the variable that shows the stronger evidence of interaction.

The results are supported by Huber's M-estimator (Huber 2009) (table 4) for each group across each of the dependent variables. These results also reveal a direct association between age and the financial health of the companies (except for the impact on variable $x 4$ of micro and small companies), which means that older companies have less risk of failure. This direct association is also found when analyzing the association between size and the dependent variables without controlling for age. However, when controlling for age, one achieve to different results (table 4). The interaction between age and size does not allow the interpretation of the impact of size alone, as interaction can confound the effect of size.

Table 4. Huber's M-estimators

\begin{tabular}{|l|l|cccc|}
\cline { 3 - 5 } \multicolumn{2}{c|}{} & $\mathrm{x} 1$ & $\mathrm{x} 2$ & $\mathrm{x3}$ & $\mathrm{x} 4$ \\
\hline Micro companies & Less than 5 years &, 077 &, 017 &, 136 &, 046 \\
& Between 5 and 15 years &, 083 &, 104 &, 262 &, 030 \\
& More than 15 years &, 076 &, 188 &, 374 &, 022 \\
\hline \multirow{2}{*}{ Small companies } & Less than 5 years &, 067 &, 002 &, 151 &, 038 \\
& Between 5 and 15 years &, 098 &, 057 &, 257 &, 034 \\
& More than 15 years &, 103 &, 176 &, 389 &, 029 \\
\hline Medium companies & Less than 5 years &, 061 &,- 199 &, 133 &, 011 \\
& Between 5 and 15 years &, 078 &, 029 &, 298 &, 031 \\
& More than 15 years &, 121 &, 188 &, 413 &, 034 \\
\hline
\end{tabular}

\section{Conclusion}

In the economic literature there are many studies to consider size and age as key variables to explain the probability of failure and growing businesses. The objective of this paper is to evaluate the impact of size and age on the financial health of textile and tourism companies, measured by economic indices. From empirical study we can draw the following conclusions.

Age has a stronger impact on the risk of failure than size. This result is not consistent with the obtained by Quirós and Lisboa (2014) and Pérez et al. (2004). However, due to the significant interaction effect present, the individual results must be controlled for the effects of the other predictor. Particularly, this is true concerning the effect of size.

The impact of size must be interpreted independently for each level of age. Whereas the effect of age is generally positive regarding the financial health of the company, the effect of size is less clear and depends on the age of the company. 
Due to the inexistence of large companies with less than 5 years, and the relative very low frequency of large companies in the sample, the analysis was performed excluding those companies. To overcome this limitation, a larger sample will be used in a future research, in order to try to have a proxy sample of every industry.

\section{References}

Altman, E. I. (1968). Financial Ratios, Discriminant Analysis and the Prediction of Corporate Bankruptcy. The Journal of Finance, 23(4), 589-609.

Altman, E. I., Haldeman, R. G. \& Narayanan P. (1977). Zeta Analysis: A New Model to Identify Bankruptcy Risk of Corporations. Journal of Banking and Finance, 1(1), 29-54.

Audretsch, D.B. \& Mahmood, T. (1995). New firm survival: new results using a hazard function. The Review of Economics and Statistics, 77(1), 97-103.

Audretsch, D.B. (2001). Research issues relating to structure, competition, and performance of small technology-based firms. Small Business Economics, 16(1), 37-51.

Beaver, W. H. (1966). Financial Ratios as Predictors of Failure. Journal of Accounting Research, Supplement, 4(3), 71-111.

Berger, A. N. \& Udell, G. F. (1995). Relationship lending and lines of credit in small firm finance. Journal of Business, 68(3), 351-381.

Buehler, S.; Kaiser, C. \& Jaeger, F. (2006). Merge or fail? The determinants of mergers and bankruptcies in Switzerland, 1995-2000. Economics Letters, 90(1), 88-95.

Calvo-Flores Segura, A. \& García Pérez De Lema, D. (2006). Tamaño, Antigüedad y Fracaso Empresarial. V Workshop de Investigación Empírica en Contabilidad Financiera, Universidad Autónoma de Madrid, octubre, 18-10.

Chen, K. C. W. \& Lee, C-W. J. (1993). Financial Ratios and Corporate Endurance: A Case of the Oil and Gas Industry. Contemporary Accounting Research, 9(2), 667-694.

Chen, R. \& Wong, K. (2004). The Determinants of Financial Health of Asian Insurance Companies. Journal of Risk \& Insurance, 71(3), 469-499.

Cummins, J. D.; Harrington, S. E. \& Klein, R. (1995). Insolvency Experience, Risk-Based Capital, and Prompt Corrective Action in Property-Liability Insurance. Journal of Banking and Finance, 19(3-4), 511-527.

European Commission (1996). Euro-Info 88/ES, March, Luxemburg. Statistical office of the European Communitie.

Evans, D. S. (1987). The Relationship between Firm Growth, Size, and Age: Estimates for 100 Manufacturing Industries. The Journal of Industrial Economics, 35(4), 567-581.

Fariñas, J. C. \& Moreno, L. (2000). Firm's Growth, Size and Age: A Nonparametric Approach. Review of Industrial Organization, 17(3), $249-265$.

Fitzpatrick, P. J. (1932). A Comparison of Ratios of Successful Industrial Enterprises with Those of Failed Firms. Certified Public Accountant, 12, October, November, December, 598-605, 656-662 \& 727-731.

Hall, B. H. (1987). The relationship between firm size and firm growth in the US manufacturing sector. Journal of Industrial Economics, $35(4), 583-605$.

Hol, S., Westgaard, S. \& Wijst, N. (2002). Capital structure and the prediction of bankruptcy. Working paper.

Holmes, S.; Dunstan, K. \& Dwyer, D. (1994). The cost of debt for small firms: evidence from Australia. Journal of Small Business Management, 32(1), 27-35.

Honjo, Y. (2000). Business failure of new software firms. Applied Economic Letters, 7(9), 575-579.

Lee, J. (2006). Family firm performance: Further evidence. Family Business Review, 19(2), 103-114.

López García, J.; Gandía Cabedo, J. L. \& Molina Llopis, R. (1998). La Suspensión de Pagos en las PYMES: Una Aproximación Empírica. Revista Española de Financiación y Contabilidad, 27(94), 71-97.

Mardia K. V. (1971). The effect of non-normality on some multivariate tests and robustness to nonnormality in the linear model. Biometrika, 58, 105-21.

Mazzi, C. (2011). Family business and financial performance: Current state of knowledge and future research challenges. Journal of Family Business Strategy, 2(3), 166-181.

Miller, D.; Le Breton-Miller, I.; Lester, R. \& Cannella, A. A. (2007). Are family firms really superior performers?. Journal of Corporate Finance, 13(4), 829-858.

Ohlson, J. S. (1980). Financial ratios and the probabilistic prediction of bankruptcy. Journal of Accounting Research, 18(1), 109-131.

Oksanen J.; Blanchet, F. G.; Kindt R.; Legendre P.; Minchin P. R.; O'Hara R. B.; Simpson G. L.; Solymos P.; Stevens M. H. H. \& Wagner H. (2013). Vegan: Community Ecology Package. R package version 2.0-9, URL: http://cran.r-project.org/web/packages/vegan/index.html

Olson C. L. (1974). Comparative robustness of six tests in multivariate analysis of variance. Journal of the American Statistical Association, 69, 894-908.

Peel, M. J. \& Peel, D. A. (1988). A Multilogit Approach to Predicting Corporate Failure. Some Evidence for the UK Corporate Sector. Omega, 16(4), 309-318.

Peel, M. J.; Peel, D. A. \& Pope, P. F. (1986). Predicting Corporate Failure. Some Results for the UK Corporate Sector. Omega, 14(1), 512.

Pérez, S. E.; Llopis, A. S. \& Llopis, J. A. S. (2004). The Determinants of Survival of Spanish Manufacturing Firms. Review of Industrial Organization, 25(3), 251-273.

Quirós, M. \& Lisboa, I. (2014). Does family control reduce firm risk?. XXIV Jornadas Luso Espanholas de Gestão Científica, 6,7,8 
february, Leiria.

R Development Core Team (2011). R: A Language and Environment for Statistical Computing. R Foundation for Statistical Computing, Vienna, Austria. ISBN 3-900051-07-0, URL http://www.R-project.org/.

Serrano Cinca, C.; Mar Molinero, C. \& Gallizo Larraz, J. L. (2005). Country and size effects in financial ratios: A European perspective. Global Finance Journal, 16(1), 26-47.

Smith, R. \& Winakor, A. (1935). Changes in Financial Structure of Unsuccessful Industrial Corporations. Bureau of Business Research, Bulletin No. 51. Urbana: University of Illinois Press.

Thompson, D. J. (1976). Sources of systematic risk in common stocks. The Journal of Business, 49(2), 173-188.

Turetsky, H. F. \& McEwen, R. A. (2001). An Empirical Investigation of Firm Longevity: A Model of the Ex Ante Predictors of Financial Distress. Review of Quantitative Finance and Accounting, 16(4), 323-343.

Villalonga, B. \& Amit, R. (2006). How do family ownership, control and management affect firm value?. Journal of Financial Economics, 80(2), 385-417. 